\title{
A model of costs of RTI case management services in Uttar Pradesh
}

\author{
Saumya RamaRao \\ Population Council \\ John Townsend \\ Population Council \\ M.E. Khan \\ Population Council
}

Follow this and additional works at: https://knowledgecommons.popcouncil.org/departments_sbsr-rh

Part of the Demography, Population, and Ecology Commons, Family, Life Course, and Society Commons, International Public Health Commons, and the Maternal and Child Health Commons How does access to this work benefit you? Let us know!

\section{Recommended Citation}

RamaRao, Saumya, John Townsend, and M.E. Khan. 1996. "A model of costs of RTI case management services in Uttar Pradesh," Asia and Near East OR/TA Project Technical Paper. New Delhi: Population Council. 


\section{A Model of Costs of RTI Case Management Services in Uttar Pradesh}

Saumya RamaRao

John W. Townsend

M.E. Khan

\section{Technical Paper}

\section{The Population Council}

Asia \& Near East

Operations Research and Technical Assistance Project

New Delhi, India

November 1996 


\section{Costs of Managing Reproductive Tract Infection in India}

The Government of India has adopted a Reproductive and Child Health $(\mathrm{RCH})$ approach as the basis of its new family welfare policy. One component of the $\mathrm{RCH}$ package is the management of reproductive tract infections (RTIs). There is evidence that considerable proportions of women in India may suffer from an RTI. Four recent studies found that from 10 to 60 percent of the women in community surveys across India report symptoms indicative of RTIs, such as excessive vaginal discharge and lower abdominal pain, which were largely confirmed by clinical exams. Studies suggest that about half the women with RTI do not present symptoms, and that RTIs are not a problem limited to high risk populations.

The Population Council's Asia and the Near East Operations Research and Technical Assistance (ANE OR/TA) Project, in collaboration with the State of Uttar Pradesh, Ministry of Health and Family Welfare, is conducting a study on the feasibility and cost of providing RTI case management at the primary care level. Based on conservative estimates of incidence of infections, costs of preventive community based IEC, and only 15 percent utilization of the public health system for RTI detection and treatment, the estimated annual cost of RTI case management at the district level (about 2 million population) would be about US\$ 64,000. The cost per district is critical as operational budget in India are defined at the district level. The State of Uttar Pradesh, for example, has 68 districts and India nearly 500 districts. Estimated costs per client served range from US\$1.75 to US\$4.30, depending on local incidence and level of clinic utilization. From the analysis, it is clear that the average annual drug budget of a Primary Health Care Centre in India, approximately US\$500, is inadequate even if used only for subsidized RTI case management.

Policy makers and programme managers are using this data to examine both the initial and continuing costs of RTI case management within the overall $\mathrm{RCH}$ package in India, with a focus on quality and sustainability. Alternatives for controlling costs include better efforts at primary prevention, partner participation to reduce reinfection, user fees, and more private sector involvement in reproductive health care. 


\title{
A Model of Costs of RTI Case Management Services in Uttar Pradesh*
}

\author{
Saumya RamaRao, John W. Townsend and M.E. Khan
}

\section{Background}

The Government of India has recently initiated a new policy for the implementation of the Family Welfare programme. In April 1996, centrally fixed targets for family planning and maternal and child health services were replaced by a decentralized participatory approach to planning and service delivery. In addition, the government adopted a Reproductive and Child Health $(\mathrm{RCH})$ package (GOI, 1996). This RCH package brings together several segregated programmes and is consistent with the recommendations of the International Conference of Population and Development held in Cairo in 1994.

One of the components of the RCH package is the management of RTIs. Currently, the specific activities and services to be offered at different levels of the health system on RTIs are being planned (GOI, 1996). The availability of personnel, facilities and supplies determines the services offered. For example, Sub-Centres can offer IEC activities for the prevention of RTIs, condoms, identification of women with RTIs, partner notification and referral. Bigger facilities such as Primary Health Centres (PHC) and Post-Partum Centres (PPC) can offer additional services such as treatment and laboratory confirmation of diseases. As part of the implementation strategy of the new policy, training and monitoring activities for different health staff are being proposed. The envisaged training is consistent with both the Target Free Approach to Family Welfare and the new interventions like screening, prevention and treatment of RTIs, including prevention of HIV/AIDS.

Research on RTIs in India has so far concentrated on community level studies measuring prevalence of various infections, women's perceptions of RTIs and health seeking behaviour. Little is known about the training and managerial requirements, service delivery issues and the potential cost of service provision. For programme and policy purposes it is critical to have information on service delivery. Typically answers are sought for the feasibility of primary care systems expanding to include prevention, diagnosis, and treatment programmes for RTIs and the need for resources within current structures (Ronald and Aral, 1992). The most basic and frequently asked question is whether the public sector can indeed provide RTI services. A second question relates to the type of case management strategy to be adopted. A third question relates to the type and amount of resources required. Other associated and important issues pertain to cost-effectiveness and programme sustainability.

It is often cited that the financial costs and technical difficulty of RTI interventions greatly outweigh the biomedical, social and programmatic costs of these diseases. In terms of cost effective interventions related to reproductive tract infections, it is suggested that one of the five most costeffective interventions is prenatal screening and treatment for maternal syphilis (World Bank, 1996). The World Bank report also indicates that a managed case of syphilis can achieve a disability-adjusted life year (DALY) for $\$ 0.10$ to $\$ 40$ depending on the prevalence of disease and the strategy used to

\footnotetext{
* The Population Council - Asia \& Near East Operations Research and Technical Assistance Project, New Delhi, India Acknowledgement

The comments and suggestions of Isabelle De Zoysa and Chris Elias are gratefully acknowledged.
} 
detect the infection. The new GOI programme is innovative and provides an opportunity to obtain information on a number of unanswered questions raised above.

There is sufficient evidence to indicate that considerable proportions of Indian women may have an RTI. The evidence is based on women's self reporting of symptoms and, clinical and laboratory examinations from several community studies (see Annexure). For example, studies from four sites (urban slums of Bombay and Baroda, rural areas of West Bengal and Gujarat) found that women reported symptoms indicative of RTIs such as excessive discharge (22 to 57\%), low backache (5 to $39 \%$ ) and lower abdominal pain (9 to 22\%) (BCC, CINI, Sewa-Rural and Streehitakarini, 1995). Clinical examinations also revealed that cervicitis (8 to 40\%), vaginitis (10-15\%) and Pelvic Inflammatory Disease (1 to $17 \%$ ) were the prominent morbidities.

Similarly clinical and laboratory examinations of rural women in Karnataka revealed that 70 percent had vaginitis, cervicitis or PID (Bhatia et al., 1996). In terms of the specific infections, the laboratory assessment indicated bacterial vaginosis (18.2\%), candidiasis $(5.2 \%)$, trichomoniasis $(7.5 \%)$, chlamydia $(.5 \%)$, gonorrhoea $(0.8 \%)$, syphilis $(1.5 \%)$, and urinary tract infections $(6.5 \%)$. Apart from the community studies, clinical and microbiological studies have also confirmed the wide prevalence of RTIs among Indian women (Luthra et al., 1992).

RTIs in Uttar Pradesh also appear to be considerable. According to the preliminary results from the PERFORM survey conducted here about 30 percent of women reported RTI like symptoms. In particular, 23 percent of the women who had recently given birth in Sitapur district, reported symptoms indicative of RTIs. A similar picture emerges from Agra district as well, where over 45 percent of ever married women reported that they were currently suffering from excessive vaginal discharge (BSUP-Agra). Discussions with gynaecologists working in Sitapur district indicates that an estimated 20-30 percent of women visiting them seek treatment for ailments ranging from profuse discharge, urinary tract infections, vaginitis to PID.

This paper develops a model of standardized RTI case management in the public sector. The model uses the guidelines prepared by the National Aids Control Organization (NACO) for the management and treatment of symptomatic patients. The rationale for this model are two fold. One, definitive cost data are not available. All that is known at the current moment suggests that RTI prevention, education, and services are less costly than treatment of the consequences of RTIs. Second, the type and magnitude of resources required to provide the services are not well defined. As a result, financing and sustainability issues remain. For these reasons, the model will estimate the additional cost of providing the new service. It will specify the various elements of service provision ranging from training to service provision and their associated costs. The paper will also discuss the costs of upscaling the service to similar sites in the districts. 


\section{Objectives}

The objectives of the paper are:

- To present the estimated costs of providing standardized RTI case management services through the public sector health structure.

- To present a model of cost representing two levels of care to illustrate the options available to program managers in planning for service delivery.

\section{Methodology}

The production process methodology which describes how resources or inputs are converted by processes to outputs and outcomes is used (Janowitz and Bratt, 1994). Thus, each component of the RTI service intervention is broken down into clusters of inputs, processes and outputs. For example, the principal inputs are personnel, clinic space and the necessary equipment. These inputs are combined and utilised to provide RTI services at the clinic. The outputs in this system include the clients who seek RTI services; the education and counselling that they receive; laboratory testing and treatment.

The model estimates the cost of adding RTI laboratory testing and treatment services to the existing health and family welfare services provided by the public health centres. As service expansion rather than setting up of a new health delivery system is the focus, only those costs incurred in the expansion will be costed in the model. Thus items such as personnel who are already in place, clinic space, and other existing supplies are not costed. The assumption is that existing inputs, particularly space and personnel, can be utilized for the new service without significant additional expense because they are under utilized.

Two types of costs are presented: fixed and variable. Fixed costs do not vary with the number of clients served and refer to expenditures on items such as equipment, training, and IEC. Unlike fixed costs, variable costs vary with the numbers of clients served. Thus this type of cost covers laboratory tests and treatment for the clients. The total cost estimate is the sum of fixed and variable costs. On each line item in the model, a range of cost estimates is provided. This is to indicate the variations in the resources used and the coverage of the service. Finally, the total cost of the service is related to the numbers of clients served in order to provide an estimate of effectiveness.

\section{Data}

Data were collected from several sources on the various input parameters. Data on the prevalence of specific RTIs and conditions were collected from various research conducted in India and are listed in the annexure. Data on health personnel's allowances and the market prices of various drugs were collected from the Operations Research field sites of the Population Council in Agra and Sitapur districts of Uttar Pradesh. Costs of equipment and supplies were collected from suppliers and users in Lucknow and New Delhi. The market costs of conducting specific laboratory tests were collected in New Delhi, Bangalore and Lucknow from medical college and commercial laboratories. These data are used as input parameters to estimate the cost of RTI service provision. 


\section{Model}

According to the Government of India guidelines, different components of RTI case management are being considered to be offered at different levels: at the community, Sub-Centre, PHC, CHC and other referral institutions (GOI, 1996). Laboratory confirmation and treatment services will be available only at Primary Health Centres (PHCs) and referral institutions such as Community Health Centres (CHC), Post-Partum Centres (PPCs) and district hospitals. Services such as condom distribution and IEC activities will be available at all the levels; the intensity of IEC activities across the levels will differ. As the model estimates the full range of activities from IEC to treatment, the sites of service provision are taken to be the block PHC and the $\mathrm{CHC}$.

Block PHCs and CHCs provide a range of preventive and curative services--MCH, FP, and curative. The block PHC covers a population of 100,000 with a staffing norm of 2 doctors, 7 paramedical and 7 administrative staff (World Bank, 1995b). Generally, there is one male doctor in position. Thus gynaecological examinations are not done by the doctors. The SIFPSA programme in Uttar Pradesh is testing the feasibility of providing gynaecological services through contracted lady doctors. These private doctors provide reproductive health services for a fee at fixed PHCs on fixed days. A CHC is the first referral unit for about three to six block PHCs. Being the first referral unit, a CHC is better staffed and equipped than a block PHC. The CHCs are meant to bridge the capacities of the larger district and sub-district hospitals and the purely outpatient and extension/promotion functions of the PHCs (World Bank, 1995b). The staffing norm for a CHC is four doctors, 13 paramedical and 8 administrative staff. One of the four doctors is usually a female physician. Unlike lower levels of health facilities the presence of a female physician who can examine women clients is an important feature of the CHC in Uttar Pradesh. Both CHCs and PHCs have laboratories which are equipped to conduct blood, urine, malaria and TB sputum tests. Examination of wet smears and simple gram staining for the detection of infections such as bacterial vaginosis, trichomoniasis and candidiasis are thus feasible in this setting. It is thus possible to provide improved RTI case management with laboratory support through block PHCs and CHCs.

Thus, it is clear that a community of 100,000 is served by both a block PHC and a CHC. The model developed in this paper envisages providing RTI case management services at both the block PHC and $\mathrm{CHC}$ levels. It estimates the cost of providing RTI case management at a PHC and at a $\mathrm{CHC}$ and by extension to the district. The activities that are provided by the two types of health centres differ according to the resources available. The following services will be provided by the block PHC: IEC activities through its health workers at the community level, laboratory tests for some RTIs, treatment, counselling and referral. The $\mathrm{CHC}$ being further removed from the community will only provide laboratory tests, treatment and counselling. 
The model is depicted in the diagram below:

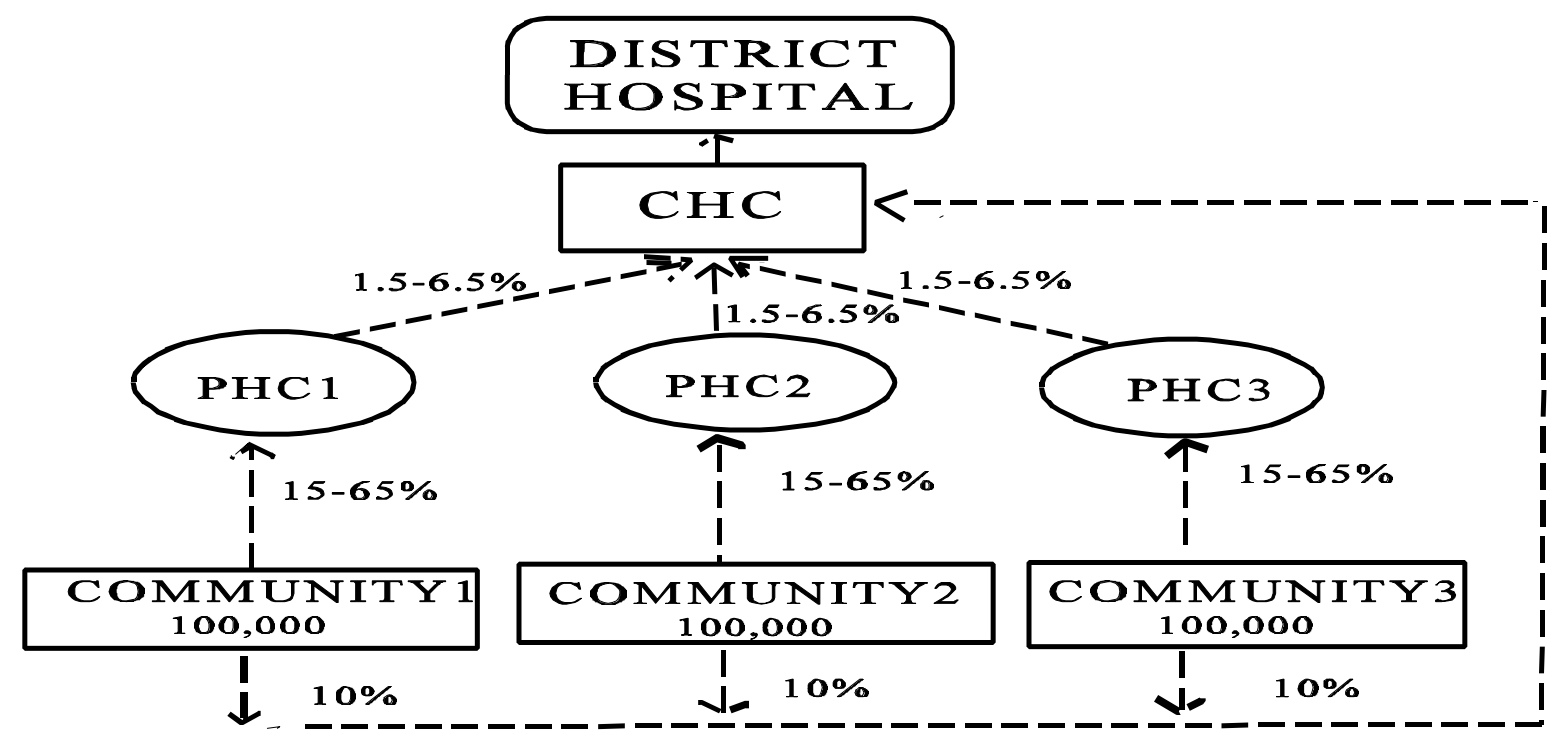

Research has indicated that not all infected individuals are aware of their morbidity and seek care; and of those seeking care, considerable proportions seek services in the non public sector. Hence, the model assumes that a minimum of twenty five percent to a maximum of seventy five percent of infected symptomatic women may seek services at various levels of the public health care: the block $\mathrm{PHC}$ and the CHC. At the block PHC, the utilisation rate varies from a minimum of 15 percent of infected individuals to a maximum of 65 percent with ten percent choosing to use the CHC. In addition, there is a referral from the block PHC to the $\mathrm{CHC}$, with about ten percent of the cases attending the block PHC being sent on to the CHC. Thus, the $\mathrm{CHC}$ would serve those clients who seek care directly and those who are referred from the PHCs. The model defines its clients as symptomatic women and for sexually transmitted diseases their partners as well. Thus according to the model service provision begins with symptomatic women seeking care and includes partners if required. The treatment costs include treatment of both partners in cases of STDs.

The cost estimates of providing the services through a $\mathrm{PHC}$ and a $\mathrm{CHC}$ are presented separately. In both models, the initial costs of setting up the service and the costs in the subsequent year are also given. It should be noted that the model is static in the sense that inflationary pressure (approximately 6-10\% annually) and seniority considerations in salary adjustments are assumed to be constant and are not included in the cost estimates. In order to highlight the range in service coverage, the model incorporates two different patterns of RTI prevalence: a low level of prevalence of all infections and a high level of prevalence of all infections (see Annexure for the two patterns). In addition it also assumes differential utilisation of the services at both the levels of service. The specific assumptions used in the model building are listed in the annexure.

\section{Results}

We first begin with estimating the cost of providing the Government of India recommended standardized case management for RTIs through a block PHC. The various activities that take place 
such as training, honorarium for the visiting female physician, capital equipment, equipment maintenance, IEC activities, quality assurance, laboratory tests and treatment are listed and costs estimated.

Table 1 presents the costs assuming a low prevalence infection pattern with 15 percent of infected clients seeking care at the PHC. The total cost in the first year is higher than in the second year due to training of personnel and equipment purchase before the services can be provided. The first year cost ranges from Rs. 121715 to Rs. 186196 or US\$ 3429-\$5245 using the exchange rate of Rs. 35.5 per US\$. Costs come down in the second year and are in the range of Rs. 58335 to Rs. 99986. In the first year, less than a quarter (17\%) of the cost is spent on the combination of training (8\% to $10 \%$ ) and purchase of capital equipment (7\% to $9 \%$ ). IEC activities constitute a significant portion of the total costs ( $46 \%$ to $54 \%$ in the first year). This allocation reflects the notion that prevention is the best form of cure, and hence the stress on educational activities at the community. The combined costs of conducting the laboratory tests (9\%) and treatment (14\%-21\%) are about a quarter of total costs.

In the second year of service delivery, the distribution of costs across the line items changes primarily due to changes in the activities. The proportion of the cost spent on IEC decreases and that spent on tests and treatment increases. Most of the IEC expenses occur in the first year. Checks on quality are a new activity in the second year and constitute about five percent of the cost. It is also clear that the cost per client served is much lower than in the first year. For example, using the minimum cost estimates, the cost per client is halved from Rs. 212 to Rs. 102 in the second and subsequent years.

The cost per client served can also be reduced with higher utilisation. Table 2 presents the total costs and cost per client served under different utilisation rates, ranging from 15 percent of infected women to 65 percent seeking services. Fixed costs remain constant while variable costs change with the numbers of clients served. With higher utilisation, fixed costs get distributed over a greater number of clients thus bringing down the cost per client served. For example, the cost per client served decreases from Rs. 157 to Rs. 102 (a 35\% decrease) when utilisation increases from 15 percent to 30 percent of infected women. However, reductions in the cost per client served are not as steep at the higher levels of utilisation. In other words, the reductions in cost per client served are large at lower levels of utilisation.

Similar to the analysis presented above, Tables 3 and 4 are based on the second infection pattern indicating the higher prevalence level of all infections. In other words, the numbers of potential clients served annually nearly doubles from 574 to 1122 . Consequently, the costs also increase but not as proportionately. For example, the total cost increases by $19 \%$ from Rs. 121715 (Table 1) to Rs.150150 (Table 3) which is less than the increase in the number of clients. In terms of the cost structure, there is a relatively higher proportion spent on laboratory testing and treatment. For example, while between a quarter to a third of the total cost was spent on these line items in the first year under the low infection scenario, these increase to two-fifths to one-half in the high infection scenario. We observe that the cost of serving a single client is also lower than in the low prevalence scenario. For example, the minimum cost of serving an average client in the first year is Rs. 212 in the first infection scenario and Rs. 134 in the second scenario. The decline in the cost per client served with greater utilisation can also be observed in Table 4, with costs dropping from Rs.106 per client at the lowest utilization level to Rs.63 at the highest utilization level. 
Tables 5 to 8 relate to the cost of RTI case management at a CHC. Recall that the services at a CHC include counselling of patients, laboratory testing and treatment. Being a First Referral Unit (FRU), outreach activities such as IEC at the level of the community are not conducted. This focus of the $\mathrm{CHC}$ is reflected in the higher proportionate share of total cost of items such as laboratory testing and treatment. Table 5 indicates that in the first year, three quarters of the total costs are attributed to laboratory testing and treatment: testing contributes 26\%-29\% and treatment 45\%-64\%. Purchase of capital equipment and IEC pamphlets are other items which consume 6 percent to 21 percent of costs. The $\mathrm{CHC}$ also serves a minimum of 1320 clients annually which is considerably higher than the load at a block PHC. The higher client load reduces the cost per client served, which is in the range of Rs. 64 to Rs. 96 in the first year. The structure of total costs in the second year is similar to the first year, with greater proportion spent on testing and treating. Total costs of the service are considerably lower than in the first year. The lowered costs are also reflected in the lower cost per client served of Rs.57 to Rs. 93.

Table 6 presents the range of total costs at the low estimates of infection prevalence under different utilisation rates. The total costs do not vary much: at the lowest utilisation level, 2640 clients can be served for Rs. 159,748 while at the highest utilisation level, 3786 clients are served for Rs. 214234. Tables 7 and 8 present a similar analysis for the higher infection prevalence pattern. The cost structure is similar to the low infection prevalence pattern.

\section{Discussion}

Thus the preceding sections presented the costs of providing RTI management services at the levels of a block PHC and a CHC. From the analysis it is clear that costs of treatment are considerable and the drug budgets of the facilities may not be adequate. For example, the average annual drug budget of a block PHC is in the range of Rs. 17000 to 20000 and RTI case management would require doubling of the existing budgets. There is a possibility of cost reductions if generic drugs are purchased at wholesale prices. However, the drug budgets have to be increased if RTI case management is to be included as a service. At the present moment, there appear to be no quantity or expenditure norms for drugs and supplies. Supply requirements do not seem to be based on the need or demand and are often inadequate and often budgets are provided on "per facility" basis which are based on the amount of funds available (World Bank, 1995b). Also, the sources and flow of drugs and supplies for specific facilities and programs are not clear. State governments purchase drugs and supplies for health facilities and at the district level, the Chief Medical Officer (CMO) decides the distribution of drugs to CHCs, PHCs and Sub-Centres. It is also not clear whether there is duplication in supply between different health and family welfare programmes or whether the supply is combined but the distribution is uneven due to higher level facilities releasing drugs to lower level ones (World Bank, 1995b).

The model also presents options about which level of the health system the services should be made available. While making services available at a lower level like the block PHC increases coverage, it makes staffing, training and quality control more difficult, resulting in inevitable cost increases. For example, the availability of the required staff such as the lab technician is crucial for service delivery. However, about fifty percent of the laboratory technicians' positions nationwide are vacant (World Bank, 1995a). There is a similar shortage of lady doctors and the contracting of private lady doctors from the private sector has to be studied in detail for sustained service delivery. Given this type of scenario, the option of providing services at a higher level of the health system where a minimum standard of care can be ensured gains strength. Another option may be to provide gynaecological 
services in a camp setting where the required technical and support systems can be arranged as is being currently done in sterilization camps. A collaborative effort of a PHC, NGOs and the Gynaecology and Obstetrics department of a city government hospital resulted in a gynaecological camp in Gujarat (Chetna, 1993). During the camp, women were clinically examined, diagnosed, treated, counselled, shown videos, and provided with educational material. The follow-up of the women was the responsibility of the local NGO. The approximate expenditure per person was worked out to be Rs. 93 (Chetna, 1993).

Another discussion point is that of upscaling and replicability. The model presented describes the activities and the cost estimates at a single block PHC and a single CHC. A district on average has 20 block PHCs and six CHCs. Based on the cost estimates presented in Tables 1 and 5, we extrapolate the potential costs at the district level. Based on the low infection scenario with the lowest level of utilization, the estimated annual cost of RTI case management at the level of block PHCs would be a minimum of Rs. 1800000 (US\$ 51000) to a maximum of Rs. 2900000 (US\$ 81000). Similarly the estimated annual cost at the level of CHCs would be in the range of Rs.480000 (US\$ 13000) to Rs. 1700000 (US\$ 47000). This implies that the annual costs at the district level of providing RTI case management at all the block PHCs and CHCs would be a minimum of Rs. 2300000 or US\$ 64000. Given that Uttar Pradesh has 68 districts it is debatable whether the state's resources can be stretched to provide RTI case management among the whole range of reproductive and child health services throughout the state. At the national level, the new Reproductive and Child Health $(\mathrm{RCH})$ approach envisages that 1.7 billion is required over a period of 5 years. Of this amount, 83 percent is allotted to meeting existing governmental norms on infrastructure supplies and personnel, while 17 percent is allotted for new services. Given this macro environment the cost of RTI case management are considerable.

Some economies of scale are possible while upscaling, such as the organization of group training sessions and the bulk purchase of equipment and supplies. Thus while total costs may decrease while upscaling, they will still remain additive. Another way to exploit the positive economies of scale would be to introduce the whole range of reproductive health services. This would then spread some fixed costs over a range of services, thus bringing down the cost of individual services.

Given that the high resource requirements, sustainability of the service is a critical issue. Sustainability would require not only commitment in terms of resources but also the willingness to continue to provide the services. It also requires that innovative ideas for cost sharing be tested. At the present moment, services provided in the public sector are free of cost. Passing on a portion of the recurring costs to some or all clients may be an option. Households spend upto five percent of their income on health care. In addition on the non availability of drugs from the public health centres, clients do purchase them in the private sector. Thus it is possible that some users may be paying users. As the greater proportion of public sector clients are economically disadvantaged, the portion of costs that could be passed on to such users has to be analysed. A second option could encourage organised sector employers to provide health care for their employees.

The paper will not be complete without a discussion of its limitations. One limitation of this model is that it aims to treat symptomatic women and through them their infected partners. Though important, issues such as treatment of asymptomatic women and men, and case screening are not addressed by this model. The rationale for this model is that it addresses the needs of symptomatic women who have so far been ignored by the programme. There is clearly a need for further information to detect asymptomatic men and women and provide the necessary management. 
A second limitation is that the outcome measure is the numbers of clients served and not clients successfully treated. This has to be so as the efficacy of treatment in the mid term is not known and there is no field experience of the syndromic approach of RTI case management. In addition, the model has not costed gold standard laboratory tests which are sensitive and specific enough to provide accurate information for diagnosis. However, the mode has costed only those tests which can be feasible in a primary health care centre.

These limitations may be reduced as pilot projects on RTI case management get underway across the country providing opportunities for information gathering. The model and the cost estimates can then be modified based on the lessons learnt from actual service delivery. Effectiveness may also improve over time with greater familiarity and ease of providing the new service. The model presented here can be used by district planners to understand the implications for decisions. The following section presents some broad conclusions based on the analysis and discussion above.

\section{Conclusions}

- The costs of RTI case management vary widely by levels of utilisation, levels of infection and the capability of health centres to provide the services.

- The model of RTI case management indicates that laboratory testing and treatment costs are higher than currently expected. However, as with other health programmes, preventive measures may be cost-effective in the long run. It stresses the importance of community outreach and IEC activities.

- The estimated total costs for RTI management are beyond existing budgets. It is possible that some cost savings are possible if the whole reproductive health package is included.

- Policy makers and programme managers need to examine both initial and continuing costs to examine the quality and sustainability of RTI case management in the context of the entire $\mathrm{RCH}$ package. 
Table 1

Costs of RTI Case Management at a PHC: Low Estimates of Infection

(In Rupees)

\begin{tabular}{|l|r|r|r|r|}
\hline \multirow{2}{*}{ Item } & \multicolumn{2}{|c|}{ Year 1 } & \multicolumn{2}{c|}{ Year 2 } \\
\cline { 2 - 5 } & Minimum & Maximum & Minimum & Maximum \\
\hline Fixed Costs & & & & \\
Training & 9740 & 18900 & 0 & 0 \\
Refresher Training & 0 & 0 & 4860 & 7670 \\
Honorarium for doctor & 6000 & 12000 & 6000 & 12000 \\
Capital & 11500 & 12200 & 0 & 0 \\
Capital Maintenance & 1150 & 1220 & 1150 & 2440 \\
IEC Activities & 66000 & 86000 & 16000 & 16000 \\
Quality Assurance & 0 & 0 & 3000 & 6000 \\
Variable Costs & 10710 & 16440 & 10710 & 16440 \\
Lab Tests & 16615 & 39436 & 16615 & 39436 \\
Treatment & 121715 & 186196 & 58335 & 99986 \\
Total Costs & 212 & 292 & 102 & 157 \\
Cost per client & & & & \\
\hline
\end{tabular}

Note: Number of clients $=574$ to 638 per year under a $15 \%$ utilisation rate. See Annexure table A-1 for the low estimates of infection of the various RTIs.

Table 2

Costs of RTI Case Management at a PHC under Different Levels of Utilization (In Rupees)

\begin{tabular}{|l|r|r|r|r|}
\hline & Fixed Costs & Variable Costs & Total Costs & $\begin{array}{c}\text { Cost per } \\
\text { Client }\end{array}$ \\
\hline $15 \%$ Utilisation & 125400 & 54650 & 180050 & 157 \\
$30 \%$ Utilisation & 125400 & 109334 & 234734 & 102 \\
$45 \%$ Utilisation & 125400 & 163348 & 288748 & 87 \\
$65 \%$ Utilisation & 125400 & 236568 & 361968 & 73 \\
\hline
\end{tabular}

Note: The costs cover a two year period and reflect the minimum estimates of fixed, variable and total costs in Table 1. The same low estimates of infection are assumed. 
Table 3

Costs of RTI Case Management at a PHC: High Estimates of Infection

(In Rupees)

\begin{tabular}{|l|r|r|r|r|}
\hline \multirow{2}{*}{ Item } & \multicolumn{2}{c|}{ Year 1 } & \multicolumn{2}{c|}{ Year 2 } \\
\cline { 2 - 5 } & Minimum & Maximum & Minimum & Maximum \\
\hline Fixed Costs & & & & \\
Training & 9740 & 18900 & 0 & 0 \\
Refresher Training & 0 & 0 & 4860 & 7670 \\
Honorarium for doctor & 6000 & 12000 & 6000 & 12000 \\
Capital & 11500 & 12200 & 0 & 0 \\
Capital Maintenance & 1150 & 1220 & 1150 & 2440 \\
IEC Activities & 66000 & 86000 & 16000 & 16000 \\
Quality Assurance & 0 & 0 & 3000 & 6000 \\
Variable Costs & & & & 25290 \\
Lab Tests & 18390 & 25290 & 18390 & 112709 \\
Treatment & 37370 & 112709 & 37370 & 182109 \\
Total Costs & 150150 & 268319 & 86770 & 146 \\
Cost per client & 134 & 215 & 77 & \\
\hline
\end{tabular}

Note: Number of clients $=1122$ to 1250 per year under at $15 \%$ utilisation rate. See Annexure table A-1 for the high estimates of the various RTIs.

Table 4

Costs of RTI Case Management at a PHC under Different Levels of Utilization

(In Rupees)

\begin{tabular}{|l|c|c|c|c|}
\hline & Fixed Costs & $\begin{array}{c}\text { Variable } \\
\text { Costs }\end{array}$ & Total Costs & Cost per Client \\
\hline $15 \%$ Utilisation & 125400 & 111520 & 236920 & 106 \\
$30 \%$ Utilisation & 125400 & 222894 & 348294 & 78 \\
$45 \%$ Utilisation & 125400 & 333936 & 459336 & 68 \\
$65 \%$ Utilisation & 125400 & 482374 & 607774 & 63 \\
\hline
\end{tabular}

Note: The costs cover a two year period and reflect the minimum estimates of fixed, variable and total costs in Table

3. The same high estimates of infection has been assumed. 
Table 5

Costs of RTI Case Management at a CHC: Low Estimates of Infection

\begin{tabular}{|l|r|r|r|r|}
\hline \multirow{2}{*}{ Item } & \multicolumn{2}{|c|}{ Year 1 } & \multicolumn{2}{c|}{ Year 2} \\
\cline { 2 - 5 } & \multicolumn{1}{|c|}{ Minimum } & Maximum & Minimum & Maximum \\
\hline Fixed Costs & & & & \\
Training & 3065 & 5775 & 0 & 0 \\
Refresher Training & 0 & 0 & 2155 & 2895 \\
Capital & 11500 & 12200 & 0 & 0 \\
Capital Maintenance & 1150 & 1220 & 1150 & 2440 \\
IEC pamphlets & 6000 & 6000 & 6000 & 6000 \\
Quality Assurance & 0 & 0 & 3000 & 6000 \\
Variable Costs & & & & \\
Lab Tests & 24660 & 75720 & 24660 & 75720 \\
Treatment & 38204 & 180164 & 38204 & 180164 \\
Total Costs & 84579 & 281079 & 75169 & 273219 \\
Cost per client & & & & \\
\end{tabular}

Note: See Annexure for the low estimates for various RTIs assumed.

The utilisation rate is $10 \%$ of direct clients plus $10 \%$ of referrals from the $15 \%$ attendees at a block PHC. Number of clients served range from 1320 to 2933 depending upon whether the PHCs covered are three or six (see Table A-2).

Table 6

Costs of RTI Case Management at a CHC under Different Levels of Utilization: Low Estimates of Infection

\begin{tabular}{|c|r|r|r|c|}
\hline & Fixed Costs & Variable Costs & Total Costs & Cost per Client \\
\hline Utilisation rate 1 & 34020 & 125728 & 159748 & 61 \\
Utilisation rate 2 & 34020 & 141876 & 175896 & 59 \\
Utilisation rate 3 & 34020 & 158434 & 192454 & 58 \\
Utilisation rate 4 & 34020 & 180214 & 214234 & 57 \\
\hline
\end{tabular}

Note: The costs cover a two year period and reflect the minimum estimates of fixed, variable and total costs in Table

5. The same low estimates of infection have been used. 
The utilisation rates refers to ten percent of the clients from each community plus a referral rate of 10 percent of the 15-65 percent attendees at a PHC (see Table A-2).

Table 7

Costs of RTI Case Management at a CHC: High Estimates of Infection

\begin{tabular}{|l|r|r|r|r|}
\hline \multirow{2}{*}{\multicolumn{1}{c|}{ Item }} & \multicolumn{2}{|c|}{ Year 1 } & \multicolumn{2}{c|}{ Year 2 } \\
\cline { 2 - 5 } & Minimum & Maximum & Minimum & Maximum \\
\hline Fixed Costs & & & & \\
Training & 3065 & 5775 & 0 & 0 \\
Refresher Training & 0 & 0 & 2155 & 2895 \\
Capital & 11500 & 12200 & 0 & 0 \\
Capital Maintenance & 1150 & 1220 & 1150 & 2440 \\
IEC pamphlets & 6000 & 6000 & 6000 & 6000 \\
Quality Assurance & 0 & 0 & 3000 & 6000 \\
Variable Costs & & & & 116160 \\
Lab Tests & 42240 & 116160 & 42240 & 517673 \\
Treatment & 85881 & 517673 & 85881 & 651168 \\
Total Costs & 149836 & 659028 & 140426 & 113 \\
Cost per client & 58 & 115 & 54 & \\
\hline
\end{tabular}

Note: See Annexure of the high estimates for various RTIs assumed.

The utilisation rate is $10 \%$ of direct clients plus $10 \%$ of referrals from the $15 \%$ attendees at a block PHC.

The number of clients served range from 2581 to 5748 depending upon whether the PHCs covered are three or six (see Table A-3). 
Table 8

Costs of RTI Case Management at a CHC under Different Levels of Utilization: High Estimates of Infection

\begin{tabular}{|l|r|r|r|c|}
\hline & Fixed Costs & $\begin{array}{c}\text { Variable } \\
\text { Costs }\end{array}$ & Total Costs & $\begin{array}{c}\text { Cost per } \\
\text { Client }\end{array}$ \\
\hline Utilisation rate 1 & 34020 & 256242 & 290262 & 56 \\
Utilisation rate 2 & 34020 & 289644 & 323664 & 55 \\
Utilisation rate 3 & 34020 & 323070 & 357090 & 55 \\
Utilisation rate 4 & 34020 & 367218 & 401238 & 54 \\
\hline
\end{tabular}

Note: The costs cover a two year period and reflect the minimum estimates of fixed, variable and total costs in Table

7. The same high estimates of infection have been used.

The utilisation rates refers to ten percent of the clients from each community plus a referral rate of 10 percent of the 15-65 percent attendees at a PHC (see Annexure table A-3).

\section{DATA AND ASSUMPTIONS}

\section{MODEL 1: PHC MODEL}

Given below are the data and assumptions on which the model is based. Calculations for each of the line items in Tables 1 to 4 are also presented. The model is presented for a two year period with the costs borne in each year presented separately. Service delivery commences in Year 1 with the initial investments in training and equipment with services continuing to be provided in the second year as well.

\section{Year 1}

\section{- Training of doctors}

The Medical Officer in Charge of the block PHC and the female physician contracted under the special visiting doctor programme undergo training in standardized case management of RTIs. The training is conducted at the nearest teaching institution. The duration of training is for a minimum of 5 days to a maximum of 7 days. The cost of training is Rs. 200 per day; this cost covers material provided, the rental of space and resource persons for the training. In addition, the physicians are given the permissible Dearness Allowance (Rs. 35 to Rs. 50 per day) and travelling allowance (Rs. 250-Rs. 350 for AC Chair car) to travel to the nearest teaching institution.

\section{- Training of laboratory technician}


The laboratory technician needs training in laboratory techniques for detecting the pathogens causing specific RTIs. The training period is for a minimum period of 7 days to a maximum of 15 days. The cost of training is Rs. 200 per day and covers the cost of materials, specimens, space rental and resource persons. The permissible allowances for laboratory technicians is a Dearness Allowance of Rs. 20-35 per day and IInd class train fare of Rs. 100-150 to the nearest teaching institution.

\section{- Training of health workers}

Health workers (male and female) posted at the block PHC have to be trained in conducting IEC activities for RTI case management at the level of the community. Health workers training will include symptoms of RTIs, modes of transmission, prevention, referral to the health centre and treatment compliance. The training will be for three days at the block PHC and will be conducted by the Medical Officer in Charge. The cost of training a health worker is estimated to be Rs. 50 per day inclusive of materials distributed and food. The workers also receive the Dearness Allowance in the range of Rs. 10-15 per day and travel allowance of Rs. 10-40 to travel from their headquarters to the block PHC.

\section{- Honorarium for the visiting doctor}

Under the visiting doctor scheme, a private female physician is contracted to visit the block PHC once or twice a week. She is paid Rs. 500 per visit as honorarium. As the rationale for the visiting doctor scheme is to provide accessible gynaecological consultation, in particular for RTIs, a portion of her honorarium is charged to the RTI services. Based on clinic data that twenty five percent of women patients seek care for RTIs, this proportion is charged to the RTI service.

\section{- Cost of equipment}

It is necessary to equip the laboratory with the minimum needed equipment so that the diagnostic services can be provided. Given below are the list of equipment with their associated market prices:

\begin{tabular}{|c|c|}
\hline Microscope & Rs. 10,000 \\
\hline Centrifuge machine & Rs. $\quad 3,000$ \\
\hline Sterilizer & 1,000 \\
\hline Hot air oven & $3,800-4,500$ depending on volume \\
\hline Burner & Rs. $\quad 200$ \\
\hline
\end{tabular}

\section{- Capital Maintenance}

10 percent of the amount spent on capital equipment is allotted for their maintenance. This varies from Rs. 1150 to Rs. 1220 depending on whether Rs. 11500 or Rs. 12200 was spent on acquiring the capital equipment.

\section{- IEC activities}

To conduct IEC activities several types of materials need to be prepared such as flip charts, pamphlets and videos. Flip charts and videos are to be used by health workers for providing information and 
communicating with the community. Pamphlets on the other hand are to be distributed to the clients who come to the CHC. The cost of manufacture of 100 flip charts is Rs. 10000. The cost of producing a video ranges between Rs. 50,000 to 70,000 inclusive of shooting, printing and making 3 copies. 3000 pamphlets can be printed at Rs. 2 per copy.

\section{- Costs of laboratory tests}

For arriving at the numbers of clients who would seek services for specific RTIs we have made three assumptions. The first assumption is there are 17,000 sexually active women in the population of 100,000 served by the PHC. The thumb rule used is of 170 eligible couples per 1000 population. The approximation of eligible women to sexually active ones has been made assuming that most sexual activity takes place within marriage.

The second assumption is about the prevalence levels of various RTIs in the general population. Existing research indicates that the range for the prevalence of syphilis is between 1 and 5 percent; gonorrhoea 1 and 2 percent; trichomoniasis affects between 8 and 13 percent of sexually active women; candidiasis affects 5-17 percent; bacterial vaginosis 15 to 18 percent; PID 8 to 17 percent; other RTIs 1-3\% (See Annexure). As on average half the women with RTIs are asymptomatic, we have used half the prevalence levels. The model presents cost estimates for two different infection patterns. The first is a low infection prevalence using the minimum values of prevalence presented above. The second variation uses the higher end of the range in prevalence rates for the various RTIs.

The third assumption pertains to the utilisation of the services. As not all women with RTIs seek services the model assumes different rates of utilisation of the RTI services. Utilisation rates range from 15 percent of women with RTIs seeking services to a 65 percent coverage. Management of women with STDs is only complete with management of partners as well. Hence the model assumes that a half to all partners of STD infected women are managed.

Based on these three assumptions, the number of potential clients with specific RTIs who are managed at the PHC are given below in Table A1 and A2. Table A1 provides the numbers of clients under a low prevalence of infection scenario and Table A2 the high prevalence of infection. The

minimum and maximum values under each utilisation column refer to the variation in the numbers of partners managed for sexually transmitted infections. Tables 1-2 are based on the numbers presented in Table A1 and Tables 3-4 based on Table A2. 
Table A-1: Number of Clients: Low Infection Scenario

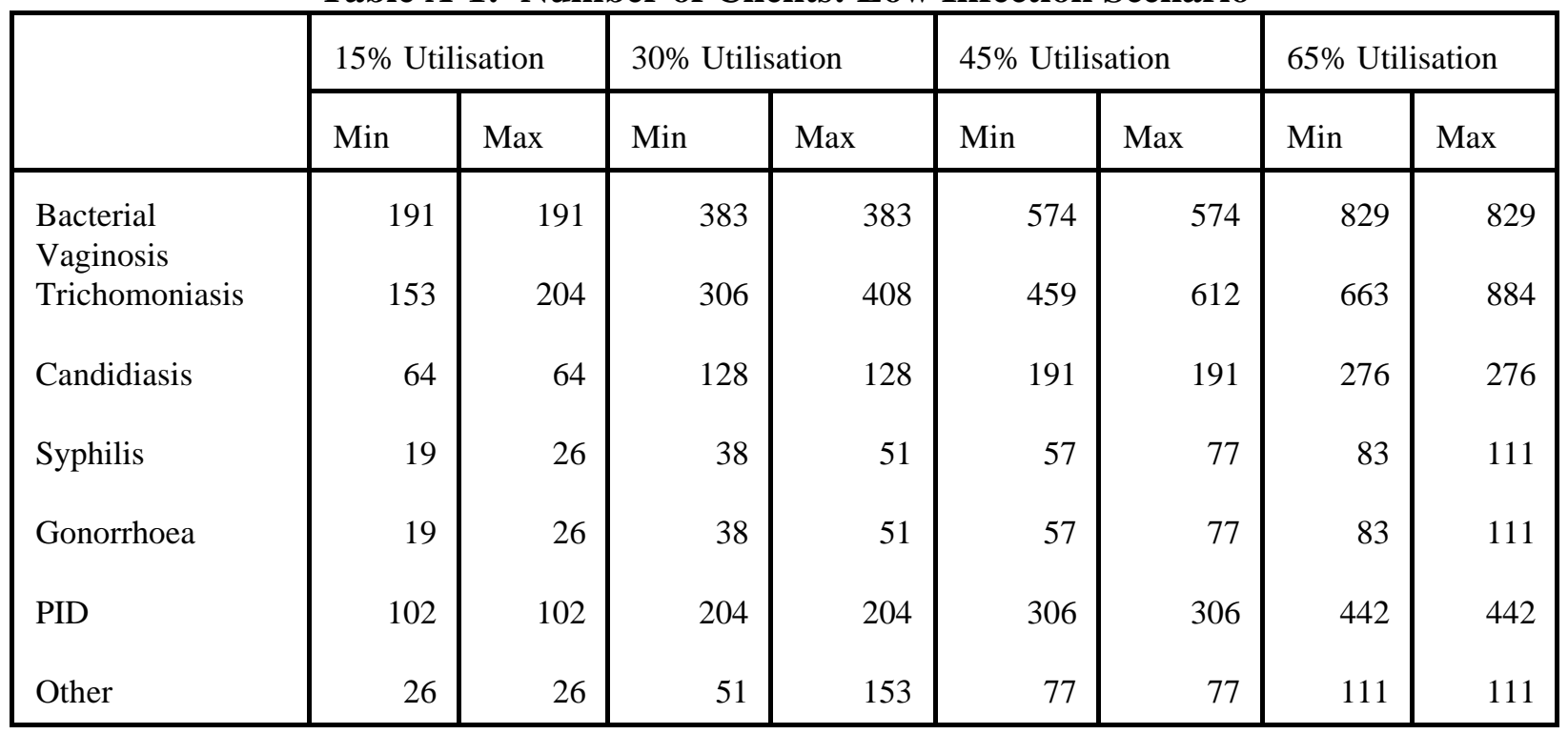

The costs of conducting a laboratory test for specific RTIs varies according to the infection and the laboratory technique followed. Some of the pathogens can be identified by simple microscopic examination of wet mounts while others may require gram staining or other procedures. The costs of laboratory detection per sample are as follows:

Bacterial Vaginosis $\quad$ Rs. 30 for wet mount to Rs. 60 for gram staining

Trichomoniasis $\quad$ Rs. 30 for wet mount

Candidiasis Rs. 30 for wet mount

Table A-2: Number of Clients: High Prevalence Scenario

\begin{tabular}{|c|c|c|c|c|c|c|c|c|}
\hline & \multicolumn{2}{|c|}{$15 \%$ Utilisation } & \multicolumn{2}{|c|}{$30 \%$ Utilisation } & \multicolumn{2}{|c|}{$45 \%$ Utilisation } & \multicolumn{2}{|c|}{$65 \%$ Utilisation } \\
\hline & Min & $\operatorname{Max}$ & Min & Max & Min & $\operatorname{Max}$ & Min & Max \\
\hline Bacterial Vaginosis & 230 & 230 & 459 & 459 & 689 & 689 & 995 & 995 \\
\hline Trichomoniasis & 249 & 332 & 497 & 663 & 746 & 995 & 1077 & 1437 \\
\hline Candidiasis & 217 & 217 & 434 & 434 & 650 & 650 & 939 & 939 \\
\hline Syphilis & 96 & 128 & 191 & 255 & 287 & 383 & 414 & 553 \\
\hline Gonorrhoea & 38 & 51 & 77 & 102 & 115 & 153 & 166 & 221 \\
\hline PID & 217 & 217 & 434 & 434 & 650 & 650 & 939 & 939 \\
\hline Other & 77 & 77 & 153 & 153 & 230 & 230 & 332 & 332 \\
\hline
\end{tabular}




\section{- Costs of treatment}

Different infections require different treatment regimes. There is a range in the costs of treatment due to different regimes and the severity of the condition. The specific regimes prescribed for each type of infection is given in the annexure. Given below are the per case costs of treatment.

$\begin{array}{ll}\text { Bacterial Vaginosis } & \text { Rs. } 9 \text { to Rs. } 22 \\ \text { Trichomoniasis } & \text { Rs. } 6 \text { to Rs. } 8.4 \\ \text { Candidiasis } & \text { Rs. } 31 \text { to Rs. } 190 \\ \text { Syphilis } & \text { Rs. } 21 \text { to Rs. } 231 \\ \text { Gonorrhea } & \text { Rs. } 8 \text { to Rs. } 94 \\ \text { PID } & \text { Rs. } 106.5\end{array}$

As trichomoniasis syphilis and gonorrhea are sexually transmitted, treatment of partners is necessary. Thus treatment costs includes the cost of treating the clients and their partners.

\section{Year 2}

In the second year of service delivery, equipment costs are not incurred. However, expenditures on other line items occur as listed below.

\section{- Refresher Training}

In order to maintain the same level of knowledge and skills, refresher training is planned for the doctors, the laboratory technician and health workers. Both doctors at the PHC undergo refresher training for three days, the laboratory technician for five to seven days, and the health workers for one day. The cost of training, and the allowances are as mentioned earlier.

\section{- Honorarium for the visiting doctor}

As mentioned earlier, 25 percent of the visiting doctor's honorarium is charged to the RTI service delivery.

\section{- Capital maintenance}

Expenses are incurred in maintaining the equipment purchased in the previous year. Costs of maintenance have been worked out to be between 10 percent to 20 percent of the original cost. The range of 10-20 percent are approximations of operating and maintaining technical and medical equipment as proposed by the WHO and the World Bank, (Janowitz and Bratt, 1994). 


\section{- IEC activities}

IEC activities continue in the second year as well. 100 Additional flip charts are made to replace older ones in disrepair. In addition, 3000 pamphlets are printed for distribution purposes. The unit costs of a flip chart (Rs. 100) and a pamphlet (Rs. 2) continue to be the same as in the previous year.

\section{- Quality Assurance}

An important element in the model is the provision for checking and maintaining the quality of the laboratory tests. Quality assurance is maintained by checking between 100 and 200 samples in the second year of service provision. The unit cost of conducting a quality check on a sample is Rs. 30 .

\section{- Costs of laboratory tests}

The costs of laboratory tests remain the same as in the previous year. Also the same number of samples are tested.

\section{- Costs of treatment}

The costs of treatment remain the same as in the previous year. The same number of clients are treated.

\section{MODEL 2: CHC MODEL}

\section{Year 1}

As in the PHC model, data and assumptions used in developing the CHC model are presented below. Only those assumptions which differ from those already presented are given. The annual costs for a two year period are given. Investments in training and equipment occur in the first year, while service provision commences in the first year and continues in the second. The model assumes that a $\mathrm{CHC}$ covers between three and six block PHCs and the communities that fall under them.

\section{- Training}

The female physician and the laboratory technician posted at the $\mathrm{CHC}$ undergo their respective training as described in the PHC model. The input data for calculating the cost of training remain the same.

\section{- Equipment}

The laboratory at the $\mathrm{CHC}$ is also provided with the equipment provided to the block PHCs within a range of Rs. 11500 and Rs. 12200.

\section{- Capital Maintenance}

10 percent of the equipment costs is allotted for annual equipment maintenance. 


\section{- IEC Material}

The only IEC material needed at the CHC are the pamphlets on RTIs to be handed to patients. 3000 pamphlets are made at Rs. 2 each. As there will be no outreach activities, the video and flip charts are not required.

\section{- Costs of laboratory tests}

For arriving at the numbers of clients who would seek services for specific RTIs we have made three assumptions. The first two are the same as in the PHC model: that there are 170 sexually active women per 1000 population; and the two patterns of infection are presumed. As before, half the prevalence rates are used to indicate the numbers of symptomatic women.

The third assumption pertains to the utilisation of the service and is slightly different from the PHC model. The model assumes that the CHC covers between three to six block PHCs. Two types of women seek services at the $\mathrm{CHC}$ : those who visit the $\mathrm{CHC}$ directly and those who are referred from the PHCs covered by the CHC. 10 percent of the infected women from each of the block PHC areas seek care directly at the $\mathrm{CHC}$. In addition, ten percent of the women seeking services at the block PHCs are referred to the CHC. As some patients are referred from the block PHCs, the variations in the utilisation of the block PHC is also reflected in the client load at the CHC. As before, a half to all partners of women with STDs are managed.

Based on these three assumptions, the number of clients (women and partners in cases of STDs) with RTIs who seek services at the $\mathrm{CHC}$ are as given below. The minimum and maximum values under each utilisation coloumn refer to the variation in the numbers of partners managed and the numbers of block PHCs covered ( 3 or 6 ). Table A-3 refers to the low prevalance pattern and Table A-4 the high prevalance pattern. Tables 5 and 6 are based on the numbers presented in Table A3. 
Table A-3: Number of Clients Under Low Infection Prevalence

\begin{tabular}{|c|c|c|c|c|c|c|c|c|}
\hline & \multicolumn{2}{|c|}{$\begin{array}{l}\text { Utilisation } \\
\text { Rate } 1\end{array}$} & \multicolumn{2}{|c|}{ Utilisation Rate 2} & \multicolumn{2}{|c|}{$\begin{array}{l}\text { Utilisation } \\
\text { Rate } 3\end{array}$} & \multicolumn{2}{|c|}{$\begin{array}{l}\text { Utilisation } \\
\text { Rate } 4\end{array}$} \\
\hline & Min & Max & Min & $\operatorname{Max}$ & Min & $\operatorname{Max}$ & Min & Max \\
\hline Bacterial Vaginosis & 440 & 880 & 497 & 995 & 555 & 1109 & 631 & 1262 \\
\hline Trichomoniasis & 352 & 938 & 398 & 1061 & 444 & 1183 & 505 & 1346 \\
\hline Candidiasis & 147 & 293 & 166 & 332 & 185 & 370 & 210 & 421 \\
\hline Syphilis & 44 & 117 & 50 & 133 & 55 & 148 & 63 & 168 \\
\hline Gonorrhoea & 44 & 117 & 50 & 133 & 55 & 148 & 63 & 168 \\
\hline PID & 235 & 469 & 265 & 530 & 296 & 592 & 337 & 673 \\
\hline Other & 59 & 117 & 66 & 133 & 74 & 148 & 84 & 168 \\
\hline
\end{tabular}

Table A-4 refers to the high prevalence of infection. The numbers presented here are used in Tables 7 and 8.

Table A-4: Number of Clients Under High Infection Prevalence

\begin{tabular}{|l|c|c|c|c|c|c|c|c|}
\hline & \multicolumn{2}{|l|}{$\begin{array}{l}\text { Utilisation } \\
\text { Rate 1 }\end{array}$} & \multicolumn{2}{l|}{ Utilisation Rate 2 } & \multicolumn{2}{l|}{$\begin{array}{l}\text { Utilisation } \\
\text { Rate 3 }\end{array}$} & \multicolumn{2}{l|}{$\begin{array}{l}\text { Utilisation } \\
\text { Rate 4 }\end{array}$} \\
\cline { 2 - 9 } & Min & Max & Min & Max & Min & Max & Min & Max \\
\hline Bacterial Vaginosis & 528 & 1056 & 597 & 1193 & 666 & 1331 & 757 & 1515 \\
Trichomoniasis & 572 & 1525 & 646 & 1724 & 721 & 1923 & 820 & 2188 \\
Candidiasis & 499 & 997 & 564 & 1127 & 629 & 1257 & 715 & 1431 \\
Syphilis & 220 & 587 & 249 & 663 & 277 & 740 & 316 & 842 \\
Gonorrhoea & 88 & 235 & 99 & 265 & 111 & 296 & 126 & 337 \\
PID & 499 & 997 & 564 & 1127 & 629 & 1257 & 715 & 1431 \\
Other & 176 & 352 & 199 & 398 & 222 & 444 & 252 & 505 \\
\hline
\end{tabular}

The costs of conducting the various laboratory tests are as given earlier. 


\section{- Costs of treatment}

The costs of treatment are as assumed earlier.

\section{Year 2}

There are some minor changes in expenditures in the second year of the CHC model.

\section{- Refresher Training}

Refresher training is provided to the CHC female physician in RTI case management and to the laboratory technician in preparing and reading slides. The doctor undergoes a three day training and the technician for five to seven days. The calculations of training costs are as given earlier.

\section{- Capital Maintenance}

The annual maintenance of capital equipment is at the rate of 10 to 20 percent of the cost of the equipment.

\section{- IEC Pamphlets}

A further 3000 copies of the educational pamphlets are printed in the second year. These are for distribution to clients. The unit cost of a pamphlet remains Rs. 2.

\section{- Quality Assurance}

As in the PHC model, 100 to 200 slides are checked for the quality of laboratory testing done. The cost of quality assurance is at the rate of Rs. 30 per lab test.

\section{- Costs of laboratory test and treatment}

The unit costs of conducting the various laboratory tests and the costs of treatment remain the same. 
ANNEXURE

\begin{tabular}{|c|c|c|c|c|}
\hline Infection/Morbidity & Self-Reported & Clinical Exam & Laboratory test & Range \\
\hline Syphilis & & & $\begin{array}{r}0.3 \%(1) \\
1 . \%-4.8 \%(6) \\
1.5 \%(5) \\
7 \%-23 \%(7)\end{array}$ & $0.3 \%-5 \%$ \\
\hline Gonorrhoea & & & $\begin{array}{l}1.5 \%(1) \\
1.6 \%(6) \\
0.8 \%(5)\end{array}$ & $0.8 \%-1.6 \%$ \\
\hline Trichomoniasis & & & $\begin{array}{r}10 \%(1) \\
13 \%(6) \\
8 \%(5)\end{array}$ & $8 \%-13 \%$ \\
\hline Candidiasis & & & $\begin{array}{r}17 \%(1) \\
14 \%(6) \\
5 \%(5)\end{array}$ & $5 \%-17 \%$ \\
\hline Bacterial Vaginosis & & & $\begin{array}{l}15 \%(1) \\
18 \%(5)\end{array}$ & $15-18 \%$ \\
\hline PID & & $\begin{array}{l}16 \%(1) \\
17 \%(2) \\
8 \%(3) \\
8 \%(4) \\
11 \%(5)\end{array}$ & & $8 \%-17 \%$ \\
\hline White discharge & $\begin{array}{l}30 \%(1) \\
61 \%(1 \mathrm{~b}) \\
50 \%(2) \\
57 \%(3) \\
22 \%(4) \\
17 \%(5) \\
22 \%(5 \mathrm{~b})\end{array}$ & & & $17 \%-61 \%$ \\
\hline Vaginitis & & $\begin{array}{l}15 \%(1) \\
4 \%(2) \\
10 \%(3) \\
11 \%(4) \\
13 \%(5)\end{array}$ & & $4 \%-15 \%$ \\
\hline Cervicitis & & $\begin{array}{l}39 \%(1) \\
14 \%(2) \\
8 \%(3) \\
14 \%(4) \\
24 \%(5)\end{array}$ & $37 \%(5)$ & $8 \%-39 \%$ \\
\hline
\end{tabular}

Note: 1. Bombay (BCC et al.); 2. W. Bengal (BCC et al.); 3. Rural Gujarat (BCC et al.); 4. Baroda (BCC et al.); 5. Karnataka (Bhatia et al.); 6. Jaipur (Pachauri); 7. Different cities and years (Luthra et al.). 


\section{Treatment Costs of Various RTIs}

\begin{tabular}{|c|c|c|c|}
\hline Infection & Treatment Regimen & Cost of Drugs & $\begin{array}{c}\text { Range of Treatment } \\
\text { Costs }\end{array}$ \\
\hline Bacterial Vaginosis & $\begin{array}{l}\text { Metronidazole } 400-500 \mathrm{mg} \text { orally twice a day for } 7 \text { days. } \\
\text { Local regimen: Metronidazole cream twice a day for } 7 \\
\text { days. }\end{array}$ & $\begin{array}{l}\text { Rs. } 6.5 \text { for } 10 \text { tablets. } \\
\text { Rs. } 5 \text { to } 22\end{array}$ & Rs. 9 to Rs. 22 \\
\hline Trichomoniasis & $\begin{array}{l}\text { Metronidazole } 200 \mathrm{mg} \text { orally } 3 \text { times a day for } 7 \text { days. } \\
\text { Single oral dose of Tinidazole } 2 \mathrm{gr} \text {. }\end{array}$ & $\begin{array}{l}\text { Rs. } 4 \text { for } 10 \text { tablets. } \\
\text { Rs. } 6\end{array}$ & Rs. 6 to Rs. 8.40 \\
\hline Candidiasis & $\begin{array}{l}\text { Single oral dose of Flucanazole } 150 \mathrm{mg} \text {. } \\
\text { or } \\
\text { Miconazole or clotrimazole } 100 \mathrm{mg} \text { intravaginally for } 6 \\
\text { days } \\
\text { Ketoconazole twice a day for } 5 \text { days. } \\
\text { Local regimen: Antifungal cream or gentian violet. }\end{array}$ & $\begin{array}{l}\text { Rs. } 32 \\
\text { Rs. } 26 \text { for } 6 \\
\text { Rs. } 140 \text { for } 10 \\
\text { Rs. } 5 \text { to } 50\end{array}$ & Rs. 31 to 190 \\
\hline Syphilis* & $\begin{array}{l}\text { Early Syphilis: Single dose of Benzathine Benzyl } \\
\text { Penicillin } 2.4 \text { MU IM. } \\
\text { Or } \\
\text { Doxycycline } 100 \mathrm{mg} \text { orally twice a day for } 15 \text { days. } \\
\text { Late Syphilis: Aqueous Procaine Penicillin G } 1.2 \text { MU IM } \\
\text { daily for } 21 \text { days. }\end{array}$ & $\begin{array}{l}\text { Rs. } 21 \text { per injection. } \\
\text { Rs. } 21 \text { for } 8 \text { tablets. } \\
\text { Rs. } 11 \text { per injection. }\end{array}$ & Rs. 21 to Rs. 231. \\
\hline Gonorrhea & $\begin{array}{l}\text { Single oral dose of Norfloxacin } 800 \mathrm{mg} . \\
\text { Or } \\
\text { Doxycycline } 100 \mathrm{mg} 2 \text { tablets for } 10 \text { days. } \\
\text { Or } \\
\text { Norfloxacin } 400 \mathrm{mg} \text { orally twice a day for } 10 \text { days. }\end{array}$ & $\begin{array}{l}\text { Rs. } 8 \text { for one tablet. } \\
\text { Rs. } 21 \text { for } 8 \text { tablets. } \\
\text { Rs. } 47 \text { for } 10 \text { tablets. }\end{array}$ & Rs. 8 to Rs. 94 \\
\hline PID & $\begin{array}{l}\text { Kanamycin } 2 \text { gr IM in single dose } \\
\text { plus } \\
\text { Doxycycline } 100 \mathrm{mg} \text { orally twice a day for } 14 \text { days } \\
\text { Metronidazole } 400 \mathrm{mg} \text { orally twice a day for } 10 \text { days. }\end{array}$ & $\begin{array}{l}\text { Rs. } 20 \text { per injection } \\
\text { Rs. } 21 \text { for } 8 \text { tablets. } \\
\text { Rs. } 6.5 \text { for } 10 \text { tablets. }\end{array}$ & Rs. 106.50 \\
\hline
\end{tabular}

Note: Treatment regimens as prescribed by the National Aids Control Organisation, SIFPSA and GOUP.

The costs of drugs are market rates as ascertained in Sitapur district and New Delhi.

* Minimum value of treatment costs are for early syphilis and maximum values treatment for late syphilis. $\square$ 


\section{References}

BCC, CINI, SEWA-Rural and Streehitakarini. 1995. "Prevalence of clinically detectable gynaecological morbidity in India: Results of four community based studies." Report presented to the Ford Foundation, New Delhi.

Bhatia, Jagdish, John Cleland, Leela Bhagvan and N. S. N. Rao. 1996. "Prevalence of gynaecological morbidity among women in South India." Report presented to the Ford Foundation, New Delhi.

BSUP-Agra. 1995. District Level Baseline Survey of Family Planning Program in Uttar Pradesh. The Population Council and Mode Research Pvt. Ltd.

Chetna. 1993. Women's Health Awareness and Diagnostic Camp. Chetna: Women's Health and Development Resource Centre.

Government of India. 1996. In-Service Training Under Family Welfare Programme. Guidelines for Developing InService Training Plan at District Level. Department of Family Welfare, Ministry of Health and Family Welfare, Government of India.

Janowitz, Barbara and John H. Bratt. 1994. Methods for Costing Family Planning Services. UNFPA and Family Health International.

Luthra, Usha K., Suman Mehta, N. C. Bhargava, Prema Ramachandran, N. S. Murthy, A. Sehgal and B. N. Saxena. 1992. "Reproductive tract infections in India: The need for comprehensive reproductive health policy and programs" in Adrienne Germain, King K. Holmes, Peter Piot and Judith N. Wasserheit (edited) Reproductive Tract Infections: Global Impact and Priorities for Women's Reproductive Health. Plenum Press: New York.

National Aids Control Organisation. 1993. Simplified STD Treatment Guidelines. NACO: New Delhi.

National Aids Control Organisation. 1993. STD Treatment Recommendations. NACO: New Delhi.

Pachauri, Saroj. 1995. Defining a Reproductive Health Package for India: A Proposed Framework. Regional Working Papers, No. 4. The Population Council: New Delhi.

Parikh, Indumati, Vijayalaxmi Taskar, Neela Dharap and Veena Mulgaonkar. 1996. "Gynaecological morbidity among women in a Bombay slum." Unpublished document. The Ford Foundation: New Delhi.

Ronald, Allan and Sevgi O. Aral. 1992. "Assessment and prioritization of actions to prevent and control reproductive tract infections in the third world," in Reproductive Tract Infections: Global Impact and Priorities for Women's Reproductive Health. Plenum Press: New York.

State Innovations in Family Planning Services Agency (SIFPSA) and Department of Health and Family Welfare, Government of Uttar Pradesh. 1995. Reproductive Health Resource Document for Uttar Pradesh. SIFPSA: Lucknow.

World Bank. 1995a. India's Family Welfare Program: Toward a Reproductive and Child Health Approach. Report No. 14644-IN. World Bank: New Delhi.

World Bank. 1995b. India: Health Policy and Finance Strategies for Strengthening Primary Health Care Services. Report No. 13042-IN. World Bank: New Delhi.

World Bank. 1996. Supplement to India's Family Welfare Program: Moving to a Reproductive and Child Health Approach. Edited by Anthony R. Measham and Richard A. Heaver. World Bank: Washington, DC. 